\title{
44605 - ULTRSOUND GUIDED AXILLARY BRACHIAL PLEXUS BLOCK: SINGLE VS TRIPLE INJECTION
}

\author{
Ngozi Imasogie, St. Josephs Health Care London, London, ON, Canada; \\ Sudha Singh, St Josephs Health Care London; \\ Kevin Armstrong, St Josephs Health Care London; \\ P Armstrong, St Josephs Health Care London; \\ S Ganapathy, St Josephs Health Care London;
}

Ultrasound-guided axillary brachial plexus block: single versus triple injection.

Introduction:

Axillary brachial plexus block is a common anesthetic technique for distal upper extremity surgery. A recent meta-analysis has shown that multiple injections are more effective than single injection. (1) Ultrasound guidance has become popular for performance of brachial plexus blocks and is associated with excellent anesthesia (2). In this prospective, randomized, double blind clinical trial we compared the effects of a single injection versus triple injection on the onset time and quality of sensory and motor block using ultrasound in patients having axillary block for surgery.

Methods:

Following Research Ethics Board approval and written informed consent, 88 adult patients undergoing upper limb surgery were randomized to one of two groups: group A received 30mls of local anesthetic posterior to the artery, at the 6 o'clock position and group B received 10mls of local anesthetic, at the 11 o'clock, 4 o'clock and 6 o'clock positions corresponding to the locations of the median, ulna and radial nerves respectively.All blocks were done using $0.5 \%$ ropivacaine with epinephrine 1:400,000.

In all patients, the musculocutaneous nerve was blocked separately with $10 \mathrm{mls}$ of local anesthetic. Total procedure time and time to complete motor and sensory block was noted by a blind observer. Patients with incomplete blocks at 30 minutes were supplemented and this was noted.

Results:

Demographics were similar between groups. (Table 1). The time to perform the block was 3 minutes faster in group $A(p=0.015$, t-test). There was no difference in the time to ready for surgery (40.0 min in group A vs. $44.2 \mathrm{~min}$ in group B). Both techniques were associated with high success rates (88.1\% in group A vs. $89.1 \%$ in group B). Data were analysed with SAS 9.1 software.

Conclusion:

In summary, when using ultrasound guidance for axillary brachial plexus block, single injection posterior to the artery (at the 6 o'clock position) is performed faster than triple injection with no difference in subsequent sensory and motor block quality. 
Table 1

\begin{tabular}{|l|l|l|l|}
\hline \multirow{2}{*}{ Block Outcomes } & \multicolumn{2}{|c|}{} & \multicolumn{1}{|c|}{ p vlaue } \\
\cline { 2 - 3 } & \multicolumn{1}{|c|}{$\begin{array}{c}\text { Group A } \\
(\mathrm{n}=42)\end{array}$} & $\begin{array}{c}\text { Group B } \\
(\mathrm{n}=46)\end{array}$ & \\
\hline $\begin{array}{l}\text { Time to perform block }(\mathrm{T} 1) \\
(\text { min) \{mean (sd)\} }\end{array}$ & $8.6(3.7)$ & $11.7(7.2)$ & .015 (t-test) $\gamma$ \\
\hline $\begin{array}{l}\text { Time to prepare patient } \\
(\mathrm{T} 1+\mathrm{T} 2) \omega \text { \{median\} }\end{array}$ & 40.0 & 44.2 & .585 (log-rank chi-square) \\
\hline $\begin{array}{l}\text { Time to prepare patient for } \\
\text { surgery - }>30 \text { Minutes } \text { \{n } \\
(\%)\}\end{array}$ & $31(73.8 \%)$ & $33(71.7 \%)$ & $\begin{array}{l}.828 \text { (Chi-square test for } \\
\text { comparing proportions) }\end{array}$ \\
\hline $\begin{array}{l}\text { Adequate for Surgery without } \\
\text { supplements }\end{array}$ & $37(88.1 \%)$ & $41(89.1 \%)$ & $\begin{array}{l}>.999 \text { (Fisher's Exact 2- } \\
\text { tailed test) }\end{array}$ \\
\hline
\end{tabular}

References:

1.Cochrane Database Syst Rev, 2006;25:CD003842

2.Ultraschall Med. 2005;26:114-9 